\title{
Cultivo de cachama blanca en altas densidades y en dos sistemas cerrados
}

\author{
Germán Poleo(1), José Vicente Aranbarrio(1), Lismen Mendoza(1) y Oneida Romero(1)
}

\begin{abstract}
(1)Universidad Centroccidental Lisandro Alvarado, Estación de Piscicultura, Apartado 400, Barquisimeto, Edo. Lara, Venezuela. E-mail: gpoleo@ucla.edu.ve, jarambarrio78@gmail.com, lismenmendoza@ucla.edu.ve, romeroney@hotmail.com
\end{abstract}

\begin{abstract}
Resumen - El objetivo de este trabajo fue evaluar la tolerancia de la cachama blanca, Piaractus brachypomus, a cultivos en altas densidades en sistemas cerrados. Novecientos alevines de $44,3 \pm 26 \mathrm{~g}$ de peso, se distribuyeron en seis tanques de concreto, con $4,8 \mathrm{~m}^{3}$ de agua. Tres tanques presentaron cero recambio de agua (SCR), y en otros tres, el agua se hizo circular a través de un bioclarificador (SRA). Ambos tratamientos presentaron fuerte aireación para mantener los sólidos en suspensión y suministrar aire. Los peces se alimentaron a saciedad con pienso comercial por 192 días. Los parámetros de calidad de agua como: oxígeno disuelto, amonio total, nitritos, nitratos, alcalinidad, dureza, temperatura y $\mathrm{pH}$, se midieron semanalmente. Los peces en el SCR crecieron a una tasa de $2,34 \pm 0,05$ g por día, y tuvieron conversión alimenticia de $1,5 \pm 0,06$, densidad final de $12,96 \pm 0,53 \mathrm{~kg} \mathrm{~m}^{-3}$, y peso final de $449,5 \pm 99 \mathrm{~g}$. En el SRA, los peces crecieron 2,33 $\pm 0,03 \mathrm{~g}$ por día, con conversión alimenticia de $1,6 \pm 0,07$, densidad final de $12,13 \pm 1,12 \mathrm{~kg} \mathrm{~m}^{-3}$, y peso final de $446,5 \pm 10 \mathrm{~g}$. La cachama blanca puede ser cultivada en sistemas cerrados con cero recambio de agua en altas densidades.
\end{abstract}

Términos para indexación: Piaractus brachypomus, biofloc, sistemas de cero recambio, sistemas de recirculación de agua, sistemas heterotróficos.

\section{High-density rearing of red-bellied pacu in two closed systems}

\begin{abstract}
The objective of this work was to evaluate the tolerance of red-bellied pacu, Piaractus brachypomus, to high-density in closed production systems. Nine hundred fingerlings with $44.3 \pm 26 \mathrm{~g}$ weight were distributed in six $4.8 \mathrm{~m}^{3}$ concrete tanks. Three tanks had zero water exchange rate (SCR), and in the other three water was connected to a bioclarifier (SRA). All tanks had strong aeration to keep solids suspended and air supply to the system. Fish were fed to satiety for 192 days with a commercial feed. Water quality parameters such as dissolved oxygen, total ammonia nitrogen, nitrites, nitrates, alkalinity, hardness, temperature and $\mathrm{pH}$ were measured weekly. Fish in the SCR had an average growth rate of $2.34 \pm 0.05 \mathrm{~g}$ per day, showed a food conversion rate of $1.5 \pm 0.06$, reached a final density of $12.96 \pm 0.53 \mathrm{~kg} \mathrm{~m}^{-3}$, and a final weight of $449.5 \pm 99 \mathrm{~g}$. In the SRA, fish grew at $2.33 \pm 0.03 \mathrm{~g}$ per day, had a food conversion rate of $1.6 \pm 0.07$, reached a final average density of $12.13 \pm 1.12 \mathrm{~kg} \mathrm{~m}^{-3}$ and a final weight of $446.5 \pm 10 \mathrm{~g}$. Red-bellied pacu can be grown in closed systems with zero water exchange at high culture densities.
\end{abstract}

Index terms: Piaractus brachypomus, biofloc, zero exchange systems, recirculating aquaculture systems, heterotrophic systems.

\section{Introducción}

En las últimas décadas se ha diseñado una serie de sistemas de producción de organismos acuáticos, orientada a disminuir la utilización del agua y de espacio, aumentando considerablemente la densidad de cultivo (Timmons et al., 2002). En uno de estos sistemas, denominado sistema verde, la obtención de una gran cantidad de fitoplancton es promovida para reducir los niveles de nitrógeno y promover la producción de oxígeno. En otro tipo de sistemas, la calidad del agua es mantenida por una mezcla de procesos fotosintéticos y bacteriológicos, donde los substratos (carbono orgánico disuelto, amonio, nitrito, nitrato) están suspendidos junto con los microorganismos (fitoplancton, bacterias heterotróficas y autotróficas) en la unidad de cultivo (Chamberlain et al., 2001; Rakocy, 2002; Azim \& Little, 2008).

Las consideraciones importantes para el diseño y operación de un sistema de crecimiento fotosintético en suspensión incluyen el efecto de la temperatura, la aireación y el mezclado, la cantidad y calidad de la materia orgánica agregada, y los niveles de tolerancia de los peces a la calidad del agua. Temperaturas tropicales $\left(27-28^{\circ} \mathrm{C}\right)$ son ideales para mantener una alta concentración de bacterias suspendidas en la 
columna de agua (Hargreaves, 2006). La alta densidad de cultivo en estos sistemas intensivos implica una alta tasa de alimentación, que se traduce en gran cantidad de materia orgánica. La materia orgánica debe mantenerse suspendida en la columna de agua mediante una fuerte agitación, para impedir su sedimentación y favorecer su exposición a las bacterias aeróbicas. Las bacterias heterotróficas se encargan de captar los complejos nitrogenados liberados por los peces y utilizarlos en su crecimiento, eliminando de esta manera la toxicidad por amonio y nitritos (Ebeling et al., 2006). Organismos acuáticos como el camarón, bagre de canal, híbrido de la lubina rayada y la tilapia han sido cultivados en este tipo de sistemas; sin embargo, no todos los organismos acuáticos soportan esas condiciones de cultivo. Los peces deben ser tolerantes al agua con altos niveles de sólidos suspendidos y tasas relativamente altas de amonio y nitritos. Estos sistemas tienen ventajas sobre otros sistemas cerrados de producción, pues, con cero recambio de agua, se reducen los costos de bombeo, se conservan nutrientes en los tanques, se reduce el volumen de los efluentes, se previene la entrada de contaminantes biológicos y patógenos, y se minimiza el escape de los peces de cultivo al ambiente (Hargreaves, 2006).

Los sistemas cerrados de producción intensiva se perciben como una alternativa para aumentar la producción de organismos acuáticos sin incrementar significativamente el uso de agua y tierras, lo que minimiza el impacto de la actividad acuícola sobre el ambiente (Serfling, 2006; Avnimelech, 2009).

En Venezuela, el sistema de cultivo tradicionalmente utilizado ha sido el semi-intensivo en lagunas de tierra. Aunque estos sistemas han dado buenos resultados, presentan limitaciones con respecto a los volúmenes de producción por unidad de área y a los espacios donde pueden ser desarrollados. En la medida que la actividad acuícola se incremente en Venezuela, la necesidad de diversificar e intensificar los modos de producción deberá aumentar.

Unos peces que presentan las características para tolerar las condiciones de sistemas fotosintéticos suspendidos son las cachamas, Colossoma macropomum Cuvier (1818), Piaractus brachypomus Cuvier (1817) y sus híbridos. Estos peces, de la familia de los carácidos, originarios de Sudamérica, se encuentran ampliamente distribuidos en todos los ríos de la cuenca del Orinoco y son de gran importancia, tanto en la pesquería fluvial venezolana como en la acuicultura.

El objetivo de este trabajo fue evaluar los parámetros de producción de la cachama blanca (Piaractus brachypomus), cultivada en sistemas cerrados y intensivos, y los parámetros fisicoquímicos del agua en esos sistemas, además de comparar los parámetros fisicoquímicos del agua $\mathrm{y}$ de producción entre cachamas cultivadas en un sistema fotosintético y uno heterotrófico.

\section{Materiales y Métodos}

La investigación se llevó a cabo en la Estación de Piscicultura, del Decanato de Agronomía de la Universidad Centro Occidental Lisandro Alvarado, ubicada en el sector Cañaveral, Yaritagua, Estado Yaracuy, Venezuela, $10^{\circ} 7^{\prime} 3^{\prime \prime} \mathrm{N}$ y $69^{\circ} 6^{\prime} 48^{\prime \prime} \mathrm{W}$, a $500 \mathrm{~m}$ de altitud. Se utilizaron seis tanques de concreto armado de $6 \mathrm{~m}^{3}(2 \times 3 \times 1 \mathrm{~m})$, los cuales se llenaron con un volumen final de $4,8 \mathrm{~m}^{3}$ de agua (Figura 1). Se colocaron al azar 900 alevines de cachama blanca ( 150 peces per tanque, 31,25 peces $\mathrm{m}^{-3}$ ), de 150 días de edad, provenientes de una población de mil peces de una misma cohorte producidos en la Estación de Piscicultura, con peso promedio de 44,28 $26,21 \mathrm{~g}$. Tres de los tanques, escogidos al azar, estaban conectados a un filtro biológico o bioclarificador (sistema de recirculación de agua, SRA), el cual contenía $0,2 \mathrm{~m}^{3}$ de perlas de polietileno de alta densidad como sustrato y, antes de sembrar los peces, se activó, añadiendo $500 \mathrm{~g}$ diarios de alimento concentrado ( $28 \%$ proteína cruda) por 15 días. Los tanques del SRA estaban conectados entre sí con tuberías de PVC, y el agua circulaba con

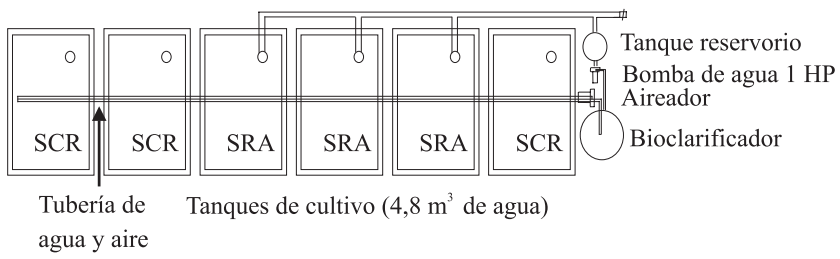

Figura 1. Esquema de los sistemas cerrados utilizados para el cultivo de cachama blanca, Piaractus brachypomus. Tres de los tanques se encontraban conectados con tubería de PVC, y el agua circulaba con una bomba de 2 HP a través de un bioclarificador; sistema de recirculación de agua (SRA) y los otros tres no tenían recirculación o sistema de cero recambio (SCR). Los seis tanques poseían un volumen útil de $4,8 \mathrm{~m}^{3}$ de agua y se les suministraba aire con un soplador de 2 HP. 
una bomba de $1 \mathrm{HP}$, conectada a un tanque reservorio que recibía el agua proveniente de los tanques de cultivo. El filtro biológico se lavó diariamente, durante el tiempo que duró el ensayo. En el sistema de cero recambio (SCR), con los otros tres tanques, el agua permaneció sin circulación; sólo fue repuesta aquella perdida por evaporación o eliminada en la retirada del sedimento de los tanques una vez a la semana ( $\sim 2 \%$ del volumen total). Todos los tanques mantuvieron una fuerte aireación, desde el fondo, con un soplador de 2 HP (Sweetwater, Apopka, FL, USA) que generaba una corriente en la superficie de $26,6 \mathrm{~cm} \mathrm{~s}^{-1}$, lo que permitió mantener las partículas como detritus, fitoplancton, zooplancton y bacterias (Biofloc) en suspensión.

Variables de producción como talla, peso, tasa de crecimiento diaria, biomasa final, porcentaje de sobrevivencia, conversión alimenticia y densidad final de producción fueron monitoreados durante 192 días. Una vez al mes, se realizó un muestreo, en el cual el 30\% del total de peces de cada tanque fue pesado con una balanza de campo modelo CS5000 (Ohaus CO., Parsippany, NJ, USA) y fueron medidas sus longitudes estándar y total con un ictiómetro, sin anestesiar a los peces. La tasa de crecimiento diaria se calculó con la fórmula: crecimiento $=($ peso final - peso inicial $) /$ días de cultivo; el porcentaje de sobrevivencia se calculó con la fórmula: sobrevivencia $=($ número de peces al final $\mathrm{x} 100)$ /número de peces al inicio. El factor de conversión alimenticia se determinó con la formula FCA = alimento consumido/ peso ganado, y la biomasa final correspondió al peso final de los peces/volumen de agua que los contenía $\left(\mathrm{kg} \mathrm{m}^{-3}\right)$. Los peces se alimentaron una vez al día a saciedad, con alimento balanceado comercial con $28 \%$ de proteína cruda Cachamarina, (Proagro C.A. Valencia, Venezuela). Para determinar el tipo de crecimiento de los peces, en ambos sistemas, y compararlo con el crecimiento en otros sistemas de producción de cachama, se estableció la relación talla-peso, mediante la ecuación de regresión $\mathrm{W}=\mathrm{qL}^{\mathrm{b}}$, en la cual $\mathrm{W}$ corresponde al peso, $\mathrm{L}$ a la longitud estándar, q es la intersección con el eje Y, y b corresponde a la pendiente de la curva (Sparre \& Venema, 1998).

Las variables fisicoquímicas del agua - oxígeno disuelto (OD), amonio total, nitritos, nitratos, alcalinidad, dureza, temperatura y $\mathrm{pH}$ - fueron monitoreadas durante 192 días. Los niveles de oxígeno disuelto en el agua, salinidad y conductividad fueron medidos diariamente con un oxímetro digital YSI, modelo 85 (YSI Inc., Yellow Spring, OH, USA) y el $\mathrm{pH}$ con un potenciómetro de campo Oakton modelo pHtestr 3 (Oakton Instruments, Vernon Hills, IL, USA). Amonio total, nitritos y nitratos se midieron semanalmente, conforme Greenberg et al. (1992), con un espectrofotómetro Aquamate (Thermo Electron Co., Cambridge, UK). La alcalinidad y la dureza se midieron semanalmente mediante titulaciones (Greenberg et al., 1992). La temperatura del agua fue registrada a cada hora por un sensor de temperatura electrónico (Onset Computer Co., Bourne, MA, USA) sumergido a $20 \mathrm{~cm}$ de la superficie.

Los resultados se expresaron como la media \pm desviación estándar. Las medias, tanto de los parámetros fisicoquímicos como de los de producción de ambos tratamientos, fueron comparadas estadísticamente mediante análisis de varianza (ANOVA) de una vía, seguido por una prueba de Tukey, con el programa estadístico SPSS (IBM, 2007). Se consideraron diferencias significativas al 5\% de probabilidad. Los datos de sobrevivencia, expresados en porcentaje, fueron transformados por el arcoseno de la raíz cuadrada, para mejorar la homogeneidad de las varianzas.

\section{Resultados y Discusión}

No se observaron diferencias significativas en los parámetros de producción, entre los peces cultivados en el SCR y los peces en el SRA (Cuadro1). La densidad final de cultivo fue aproximadamente 12,5 veces mayor que las densidades tradicionales de cultivo de cachama $\left(1 \mathrm{~kg} \mathrm{~m}^{-3}\right)$. Similar densidad de cultivo ha sido obtenida en la ceba de tilapias en sistemas con Biofloc, en la Universidad de las Islas Vírgenes, Estados Unidos (Rakocy et al., 2000), y en sistemas

Cuadro 1. Parámetros de producción de cachama blanca (Piaractus brachypomus), cultivada por 192 días, en seis tanques de $4,8 \mathrm{~m}^{3}$ de agua, en un sistema de cero recambio (SCR) y en un sistema de recirculación de agua (SRA).

\begin{tabular}{|c|c|c|}
\hline Parámetro & SCR & SRA \\
\hline No. peces & 450 & 450 \\
\hline Peso inicial $^{(1)}(\mathrm{g})$ & $47,92 \pm 28$ & $40,65 \pm 24$ \\
\hline Peso final $^{(1)}(\mathrm{g})$ & $449,5 \pm 99$ & $446,5 \pm 10$ \\
\hline Tasa de crecimiento ${ }^{(2)}$ (g por día) & $2,34 \pm 0,05$ & $2,33 \pm 0,03$ \\
\hline Densidad final $^{(2)}\left(\mathrm{kg} \mathrm{m}^{-3}\right)$ & $12,96 \pm 0,53$ & $12,13 \pm 1,12$ \\
\hline Biomasa final $(\mathrm{kg})$ & 187,97 & 176,02 \\
\hline Factor de conversión alimenticio ${ }^{(2)}$ & $1,5 \pm 0,06$ & $1,6 \pm 0,07$ \\
\hline Sobrevivencia $^{(2)}(\%)$ & $92 \pm 7$ & $87 \pm 6$ \\
\hline
\end{tabular}

${ }^{(1)}$ Media \pm desviación estándar de la población. ${ }^{(2)}$ Media \pm desviación estándar de tres replicas. 
intensivos en jaulas con C. macropomum (Chagas et al., 2007) у P. brachypomus (Granado, 2000).

Los peces crecieron, en ambos sistemas, a una tasa promedio de 2,33 g por día, la cual no difiere mucho de experiencias en cultivos intensivos de esta especie en jaulas, donde se observaron incrementos de peso diarios y una densidad final similar a la obtenida en el presente trabajo (Granado, 2000). Cultivos de C. macropomum en jaulas han mostrado tasas de crecimiento diario de hasta $4 \mathrm{~g}$ por día a densidades finales de $12 \mathrm{~kg} \mathrm{~m}^{-3}$ y $21 \mathrm{~kg} \mathrm{~m}^{-3}$ (Gomes et al., 2006; Chagas et al., 2007). Aunque sea difícil comparar el desempeño de dos distintos tipos de sistemas de cultivo, se puede afirmar que los géneros Colossoma y Piaractus pueden ser cultivados en altas densidades. Es importante señalar que no es necesariamente la densidad de cultivo la que tiene un efecto directo sobre el crecimiento de los peces (Gomes et al., 2006), sino la disponibilidad de recursos (oxígeno, alimento) y la calidad del agua (temperatura, amonio y nitritos). El factor limitante más importante, cuando se quiere aumentar la densidad de un cultivo, es la concentración de oxígeno disuelto disponible para los peces. Es por esto que en los sistemas con Biofloc, la aireación es esencial para mantener los niveles de oxígeno disuelto, requeridos por los peces y por las bacterias, las cuales se encargan de la eliminación de los complejos nitrogenados de la descomposición aeróbica de la materia orgánica y de la nitrificación. La aireación también ayuda a mantener los sólidos en suspensión que disminuyen las posibilidades de formación de zonas de descomposición anaeróbicas.

En total, se produjeron $363,99 \mathrm{~kg}$ de pescado en $36 \mathrm{~m}^{2}$ de superficie. En cultivos semi-intensivos en lagunas $\left(0,8-1 \mathrm{~kg} \mathrm{~m}^{-2}\right)$ se requeriría al menos $455 \mathrm{~m}^{2}$ de superficie para producir la misma biomasa (Juárez-Palacios, 1989; Silva-Acuña \& Guevara, 2002). Los peces no dejaron de crecer durante el tiempo que duró la experiencia; sin embargo, en los dos últimos meses, se observó una disminución en la tasa de crecimiento (Figura 2), que no pudo ser explicada con los parámetros medidos en este trabajo. No se observó mortalidad, en ninguno de los tanques, durante la experiencia; no obstante, durante las primeras cinco semanas, algunos peces saltaron fuera de los tanques, lo que afectó los porcentajes de sobrevivencia (Cuadro 1). La conversión alimenticia, observada en este trabajo, fue menor que la obtenida en experiencias con cultivos de tilapia nilótica en sistemas de Biofloc (Rakocy et al., 2000; Azim \& Little, 2008) o la obtenida en cultivos en jaulas flotantes de C. macropomum (Gomes et al., 2006; Chagas et al., 2007) y P. brachypomus (Granado, 2000).

Todos los parámetros de calidad de agua se mantuvieron en rangos aceptables (Cuadro 2) para el cultivo de la cachama blanca, en los dos sistemas

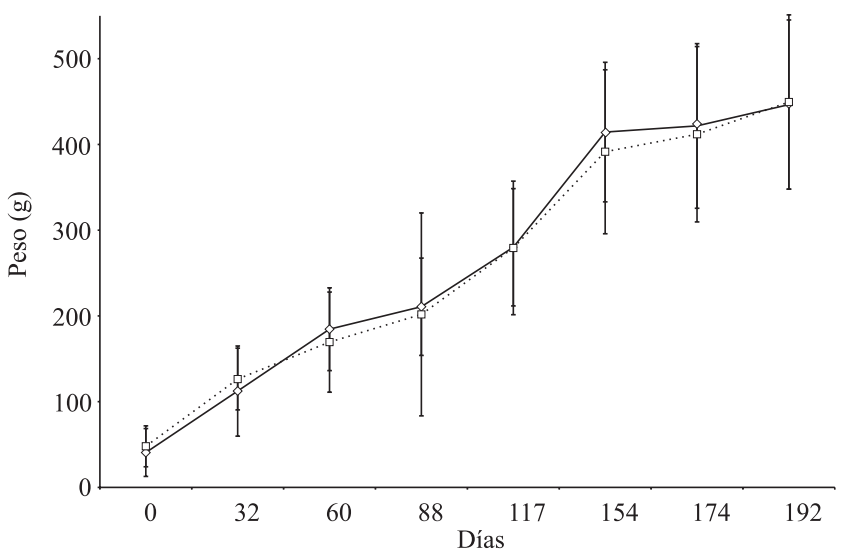

Figura 2. Curva de crecimiento de cachama blanca (Piaractus brachypomus), cultivada en un sistema de cero recambio (SCR *⿶*) y en un sistema de recirculación de agua $(\mathrm{SRA} \smile$ ) durante 192 días. Media \pm desviación estándar de tres tanques.

Cuadro 2. Parámetros de calidad de agua, obtenidos semanalmente durante 192 días de cultivo de cachama blanca (Piaractus brachypomus), en un sistema de cero recambio (SCR) y en un sistema de recirculación de agua (SRA).

\begin{tabular}{|c|c|c|c|c|c|c|}
\hline \multirow[t]{2}{*}{ Parámetro } & \multicolumn{3}{|c|}{ SRA } & \multicolumn{3}{|c|}{ SCR } \\
\hline & Media & Mínimo & Máximo & Media & Mínimo & Máximo \\
\hline Oxígeno disuelto $\left(\mathrm{mg} \mathrm{L}^{-1}\right)$ & 5,0 & 3,3 & 6,6 & 4,8 & 2,5 & 6,8 \\
\hline $\mathrm{pH}$ & 7,6 & 6,1 & 8,3 & 7,8 & 6,4 & 8,4 \\
\hline Amonio total $\left(\mathrm{mg} \mathrm{L}^{-1}\right)$ & 0,08 & 0,0 & 0,41 & 0,10 & 0,0 & 0,51 \\
\hline Nitrito (mg L-1) & 0,49 & 0,0 & 2,18 & 0,69 & 0,07 & 2,05 \\
\hline Nitrato $\left(\mathrm{mg} \mathrm{L}^{-1}\right)$ & 13 & 0,4 & 51,4 & 16,7 & 5,3 & 58,6 \\
\hline Alcalinidad (mg L-1) & 147,3 & 51,3 & 261,3 & 127,9 & 45,6 & 222 \\
\hline Dureza (mg L-1) & 457,8 & 290,7 & 552,9 & 458,7 & 348 & 570 \\
\hline Temperatura $\left({ }^{\circ} \mathrm{C}\right)$ & 27,4 & 23,6 & 31,5 & 26,9 & 22,9 & 34,4 \\
\hline Cambio de agua diario $(\%)$ & & 5,0 & & & 1,8 & \\
\hline
\end{tabular}


utilizados (Gonzáles \& Heredia 1998). Esto evidenció que el sistema de recirculación de agua con filtración biológica, diseñado en este experimento no mostró ninguna ventaja sobre el SCR. Los niveles promedios de OD se mantuvieron superiores a $4 \mathrm{mg} \mathrm{L}^{-1}$, en ambos sistemas, y no mostraron diferencias significativas $(\mathrm{p}=0,58)$. Sin embargo, se observó una ligera disminución en la concentración de oxígeno disuelto, en las primeras semanas de cultivo, en ambos sistemas. Estos cambios se pueden atribuir al incremento en el consumo de alimento por los peces en crecimiento y al aumento en la concentración de plancton y bacterias en el sistema. A partir de la décima semana, las concentraciones de OD en ambos sistemas disminuyeron rápidamente y alcanzaron un mínimo de 2,5 $\mathrm{mg} \mathrm{L}^{-1}$ en el SCR y $3,3 \mathrm{mg} \mathrm{L}^{-1}$ en el SRA (Figura 3). Esta disminución de los niveles de OD se debió a la obstrucción de los orificios de salida del aire en la tubería de PVC, debido a la acumulación de materia orgánica, comprobada cuando su limpieza trajo como consecuencia un rápido aumento en las concentraciones de OD. En los sistemas de producción con fuerte aireación, las concentraciones de oxígeno disuelto son mas estables durante todo el día que en los sistemas semi-intensivos, en los cuales se pueden observar niveles de OD hasta $20 \mathrm{mg} \mathrm{L}^{-1}$ durante la tarde, y $2 \mathrm{mg} \mathrm{L}^{-1}$ durante la mañana, dependiendo de la concentración de fitoplancton que tengan las lagunas (Boyd, 1990). La estabilidad en la concentración de OD puede resultar en mejores tasas de crecimiento (Boyd \& Clay, 2002).

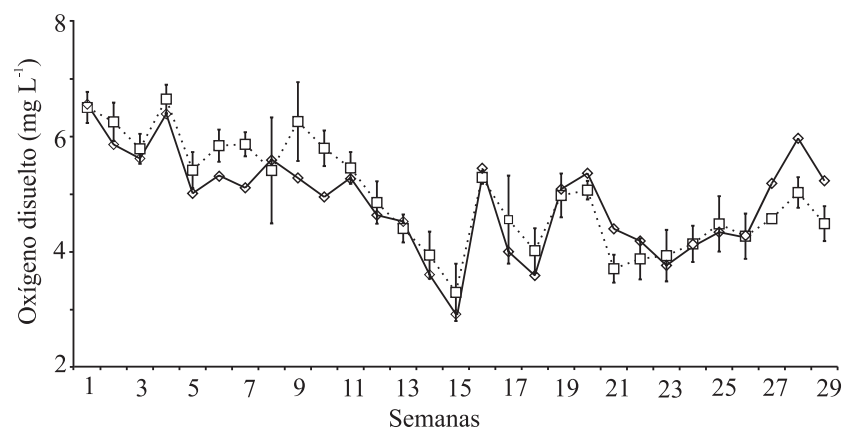

Figura 3. Concentraciones de oxígeno disuelto en el agua, obtenidos durante 192 días de cultivo de cachama blanca (Piaractus brachypomus), en un sistema de cero recambio (SCR -...) y en un sistema de recirculación de agua $(\mathrm{SRA} \smile)$.
No se observaron diferencias significativas entre los dos sistemas con respecto a las concentraciones de amonio total, las cuales se mantuvieron inferiores a $0,8 \mathrm{mg} \mathrm{L}^{-1}$ (Figura 4). Las concentraciones de nitritos se mantuvieron inferiores a $2 \mathrm{mg} \mathrm{L}^{-1}$ y se observaron diferencias significativamente menores en los SCR, solo en algunas semanas $(\mathrm{p} \leq 0,05)$.

Aunque los peces estuvieron durante algunas semanas en aguas con concentraciones de nitritos superiores a $1 \mathrm{mg} \mathrm{L}^{-1}$, no se observó mortalidad. Sin embargo, estas altas concentraciones pudieron influir sobre el crecimiento de la especie y tener un impacto negativo en los parámetros de producción. Se ha observado que $C$. macropomum es poco tolerante a bajas concentraciones de nitritos (Costa et al., 2004).
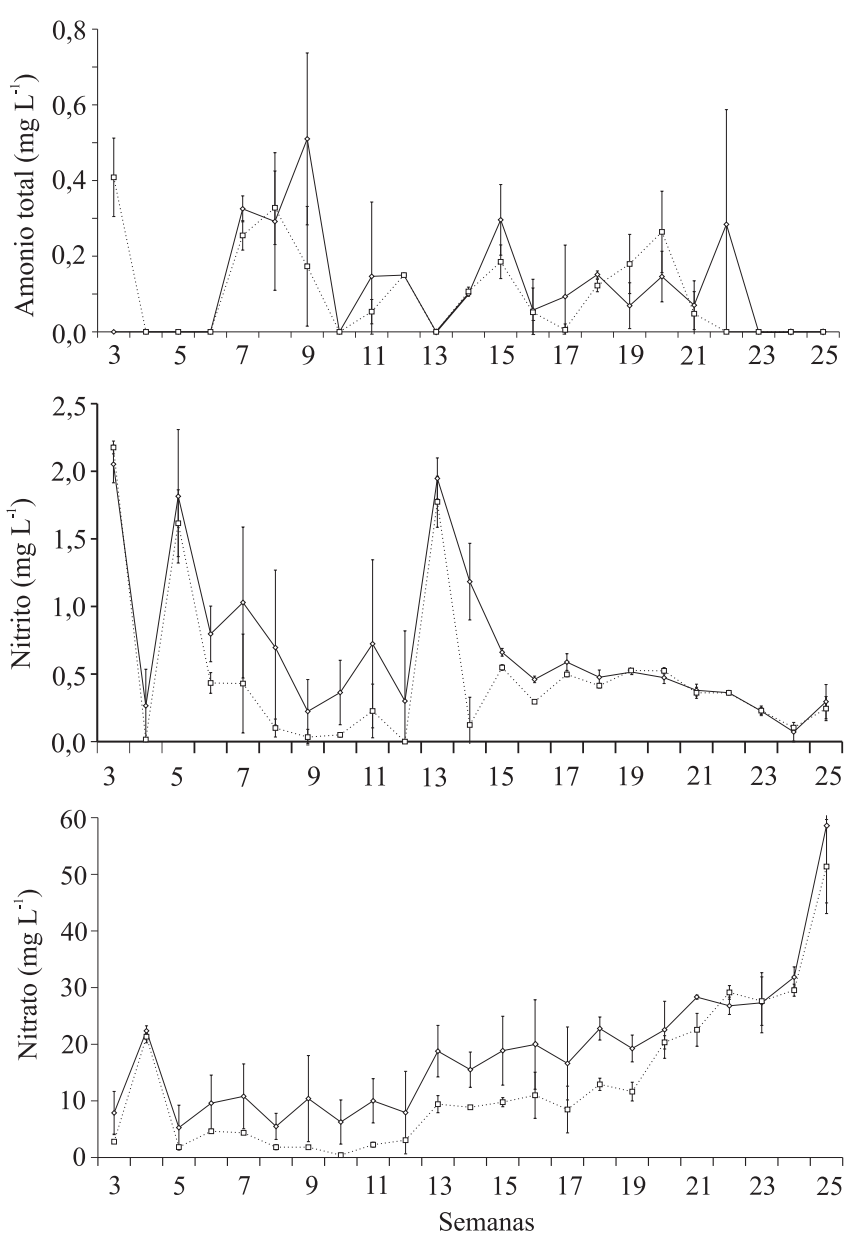

Figura 4. Concentración de amonio total, nitrito y nitratos, obtenidos durante 192 días de cultivo de cachama blanca (Piaractus brachypomus) en un sistema de cero recambio $(\mathrm{SCR} \cdots \cdots \cdot)$ y en un sistema de recirculación de agua (SRA $ヶ)$. 
Concentraciones de $0,28 \mathrm{mg} \mathrm{L}^{-1}$ ya comienzan a ser letales para esta especie. Sin embargo, la toxicidad del amonio o de los nitritos varía con la especie, el tamaño y la composición iónica del agua. Por ejemplo, las tilapias comienzan a morir, cuando las concentraciones de amonio no ionizado $\left(\mathrm{NH}_{3}-\mathrm{N}\right)$ alcanzan valores de $2 \mathrm{mg} \mathrm{L}{ }^{-1}$ y las concentraciones de nitritos $\left(\mathrm{NO}_{2}-\mathrm{N}\right)$ sobrepasan los $5 \mathrm{mg} \mathrm{L}^{-1}$ (Rakocy, 1989).

Aunque en este trabajo no se hayan estimado las concentraciones de fitoplancton ni de bacterias, el cambio en la coloración del agua, de verde a marrón intenso, que ocurrió alrededor de la semana 15 , en ambos sistemas, sugiere el paso de un sistema dominado por el fitoplancton (fotosintético) a uno dominado por bacterias (heterotrófico). A medida que aumentó la cantidad de alimento suministrado, la cantidad de carbono orgánico y nitrógeno también aumentó, lo que favoreció la proliferación de bacterias heterotróficas sobre el fitoplancton (Ebeling et al., 2006; Hargreaves, 2006; Avnimelech, 2009). Muy probablemente, la eliminación del amonio, en las primeras 15 semanas del ensayo, estuvo dominada por el metabolismo del fitoplancton y luego por las bacterias heterotróficas, en ambos sistemas. Una ventaja de los sistemas heterotróficos sobre los fotosintéticos es que la inmovilización del nitrógeno, por parte de las bacterias heterotróficas, ocurre mucho mas rápido que en la nitrificación, debido a que la tasa de crecimiento y la biomasa microbiana es mucho mayor que la de las bacterias nitrificantes o la del fitoplancton (Hargreaves, 2006; De Schryver et al., 2008). Esto pudiera explicar la fluctuación en las concentraciones de nitritos, en las primeras 15 semanas, en ambos sistemas, las cuales se estabilizaron a partir de la semana 17 , cuando ambos sistemas se pudieron considerar como heterotróficos. El cambio, en la composición microbiana del agua, en ambos sistemas, también se reflejó en los niveles de nitrato observados. Durante las primeras 13 semanas, las concentraciones de nitrato se mantuvieron relativamente estables en ambos sistemas, con una tendencia a observarse menores concentraciones en el SCR. Esta relativa estabilidad indicó su incorporación en el metabolismo del fitoplancton, mientras éste dominaba en los sistemas. Pero en la medida que cambiaban de fotosintéticos a heterotróficos, los nitratos se fueron acumulando hasta llegar a concentraciones de $58,6 \mathrm{mg} \mathrm{L}^{-1}$ (Cuadro 2). En principio, los peces toleran altas concentraciones de nitratos; sin embargo, se ha observado que concentraciones de 600 o $700 \mathrm{mg} \mathrm{L}^{-1}$ afectam el consumo de alimento en tilapias (Rakocy et al., 2000).

No se observaron diferencias significativas en los niveles de alcalinidad $(\mathrm{p}=0,11)$ ni de dureza $(p=0,87)$ entre los dos sistemas (Figura 5); sin embargo, en el SRA se observó una tendencia a ser menos alcalino que el SCR, tal vez por la mayor capacidad de nitrificación contenida en el biofiltro. Los niveles de alcalinidad, en ambos sistemas, disminuyeron a partir de la semana 16. La reducción en los niveles de alcalinidad, en los sistemas cerrados de producción, está asociado al proceso de nitrificación (McIntoch, 2000, 2001; Hargreaves, 2006), debido a que las bacterias autotróficas utilizan el carbono inorgánico en
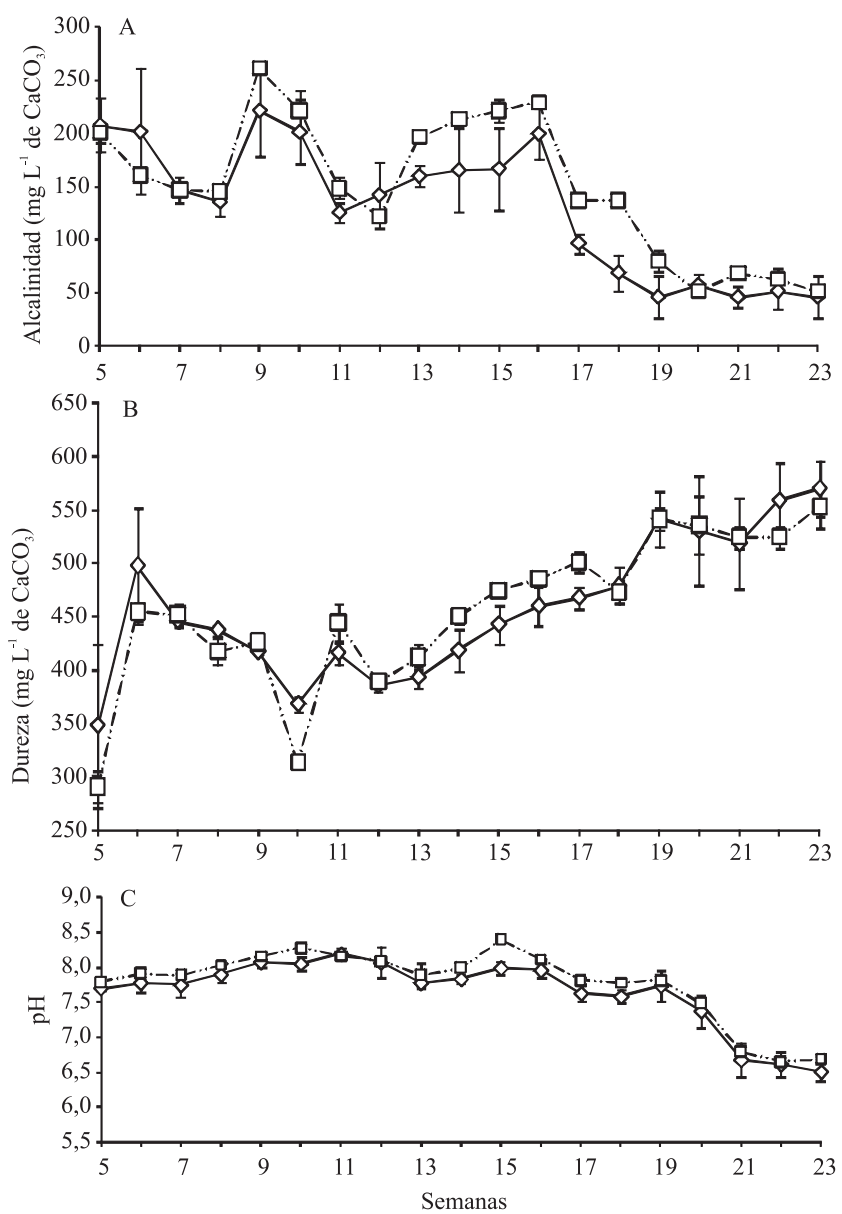

Figura 5. Alcalinidad y dureza de $\mathrm{CaCO}_{3}$ y $\mathrm{pH}$, obtenidos durante 192 días de cultivo de cachama blanca (Piaractus brachypomus) en un sistema de cero recambio (SCR *曰**) y en un sistema de recirculación de agua $(\mathrm{SRA} \smile)$. 
su metabolismo. Cerca de $355 \mathrm{~g}$ de alcalinidad, como carbonato de calcio $\mathrm{kg}^{-1}$ de alimento suministrado, es consumida por las bacterias autotróficas, de los cuales sólo el $6 \%$ es utilizado para la producción de biomasa, y el resto es liberado como $\mathrm{CO}_{2}$ (Ebeling \& Timmons, 2008). Un aumento considerable en las concentraciones de $\mathrm{CO}_{2}$, proveniente de la disociación del bicarbonato, puede causar una disminución importante del $\mathrm{pH}$. Esta situación se pudo evidenciar en el ensayo a partir de la semana 15, cuando el pH en ambos sistemas disminuyó acompañando la disminución de la alcalinidad. La acumulación de altas concentraciones de $\mathrm{CO}_{2}$ disuelto puede afectar algunas especies acuáticas (Ebeling et al., 2006), pero los peces toleran altas concentraciones de $\mathrm{CO}_{2}$, en presencia de altos niveles de oxígeno (Boyd, 1990). En los sistemas utilizados en el presente trabajo, esto se logró a través de la fuerte aireación.

La dureza del agua aumentó durante el experimento, probablemente debido a la acumulación de calcio proveniente del alimento suministrado, el cual contiene entre sus ingredientes carbonato y fosfato de calcio.

La temperatura del agua es una variable importante en el cultivo de peces y está directamente relacionada con los procesos fisiológicos como tasa de respiración, eficiencia en la alimentación y asimilación, crecimiento, comportamiento y reproducción (Timmons et al., 2002). Cada especie de pez tiene un rango de temperatura óptima en el cual se favorece su crecimiento. La cachama blanca es considerada un pez de aguas cálidas, que alcanza su máximo desarrollo en temperaturas entre los 28 y $31^{\circ} \mathrm{C}$ (Gonzáles \& Heredia 1998). Aunque la temperatura promedio observada se encuentra en el rango ideal para el cultivo de la cachama, durante la investigación se observaron temperaturas del agua inferiores a $\operatorname{los} 24^{\circ} \mathrm{C}$, las cuales podrían haber afectado las tasas de crecimiento obtenidas, ya que se reportan tasas de crecimiento para la cachama blanca de hasta $11,50 \mathrm{~g}$ por día (Silva-Acuña \& Guevara 2002).

El SCR funcionó con un recambio diario de agua de $1,8 \%$, lo que significó la producción de $1 \mathrm{~kg}$ de cachama blanca por cada $341 \mathrm{~L}$ de agua utilizados, y en el SRA se observó un recambio de agua de 5\% diario, como consecuencia del lavado diario del filtro biológico, lo que correspondió a utilizar $867 \mathrm{~L}$ de agua por kilogramo de cachama blanca producida. Se evidencia el ahorro del recurso agua, cuando se compara con un sistema de cultivo en lagunas de arcilla, en el cual unos $21.000 \mathrm{~L}$ de agua se requieren para producir un kilogramo de pescado (Timmons et al., 2002).

Las cachamas que se cosecharon, en el presente trabajo, tenían una forma aparentemente más compacta que aquellas cultivadas de forma semi-intensiva. Para comprobar esta observación, se analizó la relación talla peso, la cual mostró que los peces tuvieron un crecimiento alométrico mayorante (Figura 6) en ambos sistemas. Lo anterior indica que las cachamas blancas, bajo las condiciones de cultivo utilizadas en esta investigación, aumentaron en peso a una tasa mayor a la requerida para mantener constantes las proporciones del cuerpo. Resultados similares han sido reportados
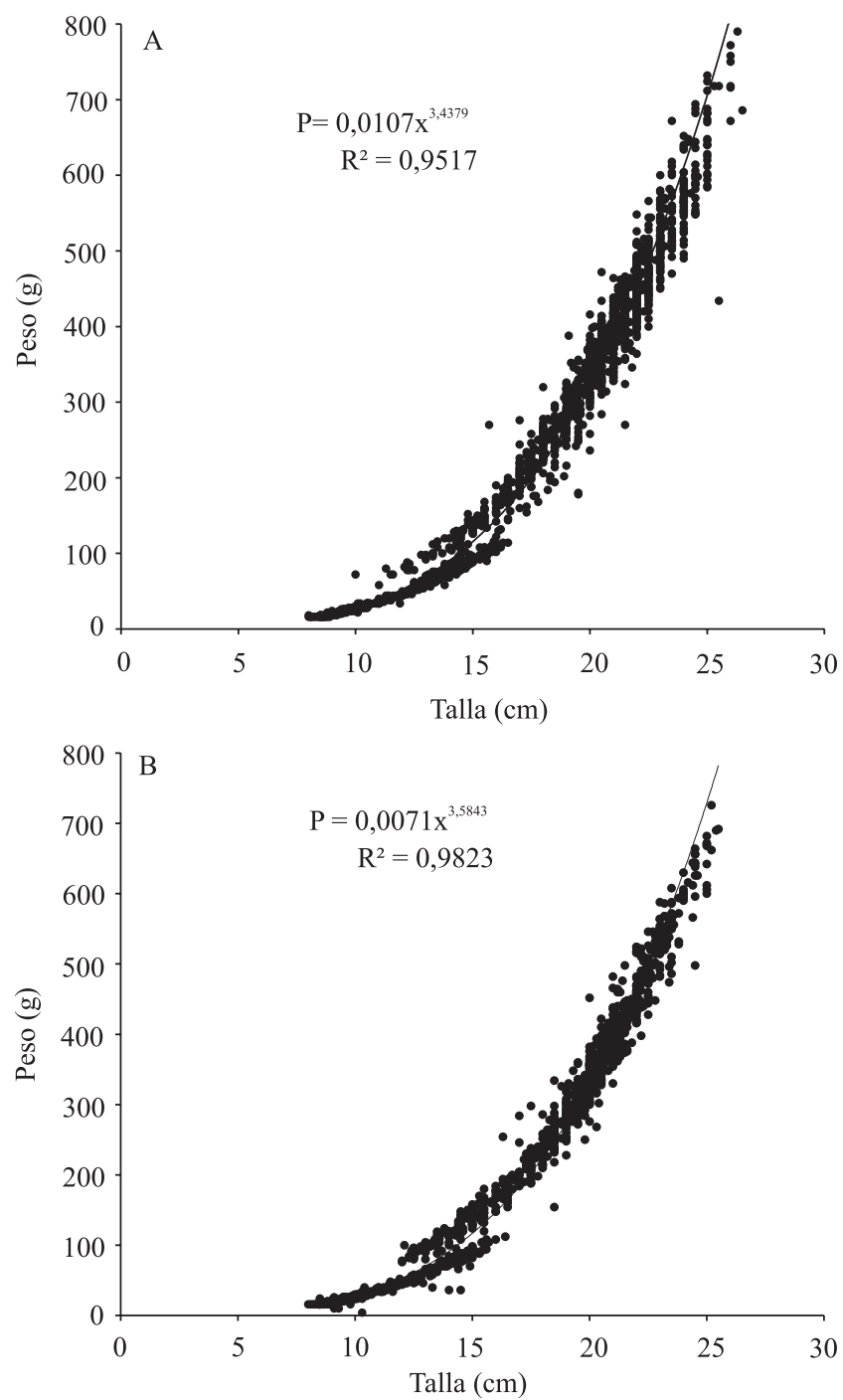

Figura 6. Relación talla peso de cachama blanca (Piaractus brachypomus), cultivada en un sistema de cero recambio (A) y en un sistema de recirculación de agua (B) durante 192 días. 
sobre $P$. brachypomus y $C$. macropomum, en cultivos en tanques en altas densidades (Prada, 1982). Por el contrario, en sistemas semi-intesivos en lagunas de arcilla, se ha observado crecimiento alométrico minorante, en el hibrido de C. macropomum (q) x P. brachypomus (ठ) (Silva-Acuña \& Guevara 2002; Bautista et al., 2005) y en peces silvestres del genero Colossoma (Villacorta-Correa \& Saint-Paul, 1999), lo que sugiere que la densidad de cultivo podría estar influenciando la forma como se desarrolla la cachama blanca.

\section{Conclusiones}

1. La cachama blanca puede tolerar densidades de cultivo de hasta $12,9 \mathrm{~kg} \mathrm{~m}^{-3}$ en los sistemas cerrados.

2. El sistema de recirculación de agua (SRA) no muestra beneficios sobre el sistema de cero recambio (SCR), lo que significa una ventaja del SCR sobre el SRA, porque se reducen los costos de instalación y operación al no requerir filtros biológicos ni bombas de agua.

3. Los sistemas cerrados presentan bajo consumo de agua y alta biomasa de peces por unidad de área.

\section{Agradecimientos}

Al Consejo de Desarrollo Científico, Humanístico y Tecnológico, de la Universidad Centroccidental Lisandro Alvarado, y al Fondo Nacional de Ciencia, Tecnología e Innovación, por el soporte financiero; a Gosmyr Torres, por el análisis estadístico; a Lue Merú Marcó, por la revisión del manuscrito; y al personal de la Estación de Piscicultura, de la Universidad Centroccidental Lisandro Alvarado, por su valiosa colaboración.

\section{Referencias}

AVNIMELECH, Y. Biofloc technology: a practical guide book. Baton Rouge: The World Aquaculture Society, 2009. 181p.

AZIM, M.E.; LITTLE, D.C. The biofloc technology (BFT) in indoor tanks: water quality, biofloc composition, and growth and welfare of Nile tilapia (Oreochromis niloticus). Aquaculture, v.283, p.29-35, 2008.

BAUTISTA, E.O.; PERNÍA, J.; BARRUETA, D.; USECHE, M. Pulpa ecologica de café ensilada en la alimentación de alevines del híbrido cachamay (Colossoma macropomum x Piaractus brachypomus). Revista Científica, v.15, p.33-40, 2005
BOYD, C.E. Water quality in ponds for aquaculture. Birmingham: Auburn University, Alabama, 1990. 482p.

BOYD, C.E.; CLAY, J. Evaluation of Belize aquaculture, Ltd.: a superintensive shrimp aquaculture system. Rome: FAO, 2002. 17p.

CHAGAS, E.C.; GOMES, L. de C.; MARTINS JÚNIOR, H.; ROUBACH, R. Produtividade de tambaqui criado em tanque-rede com diferentes taxas de alimentação. Ciência Rural, v.37, p.1109-1115, 2007.

CHAMBERLAIN, G.; AVNIMELECH, Y.; MCINTOSH, R.P.; VELASCO, M. Advantages of aerated microbial reuse systems with balanced C:N. III: practical applications. Global Aquaculture Advocate, v.4, p.50-54, 2001.

COSTA, O.T.F. da; FERREIRA, D.J. dos S.; MENDONÇA, F. Lo P.; FERNANDES, M.N. Susceptibility of the Amazonian fish, Colossoma macropomum (Serrasalminae), to short-term exposure to nitrite. Aquaculture, v.232, p.627-636, 2004.

DE SCHRYVER, P.; CRAB, R.; DEFOIRDT, T.; BOON, N.; VERSTRAETE, W. The basics of bio-flocs technology: the added value for aquaculture. Aquaculture, v.277, p.125-137, 2008.

EBELING, J.M.; TIMMONS, M.B. Carbon: nitrogen balance impacts nitrogen removal processes in microbial-based aquaculture systems. Global Aquaculture Advocate, v.11, p.38-40, 2008.

EBELING, J.M.; TIMMONS, M.B.; BISOGNI, J. Engineering analysis of the stoichiometry of photoautotrophic, autotrophic, and heterotrophic removal of ammonia-nitrogen in aquaculture systems. Aquaculture, v.257, p.346-358, 2006.

GOMES, L. de C.; CHAGAS, E.C.; MARTINS-JUNIOR, H.; ROUBACH, R.; ONO, E.A.; LOURENÇO, J.N. de P. Cage culture of tambaqui (Colosssoma macropomum) in a central Amazon floodplain lake. Aquaculture, v.253, p.374-384, 2006.

GONZÁLES, J.A.; HEREDIA, B. El cultivo de la cachama (Colossoma macropomum). 2.ed. Maracay: Fondo Nacional de Investigaciones Agropecuarias, 1998.134p.

GRANADO, A. Efecto de la densidad de cultivo sobre el crecimiento del morocoto, Piaractus brachypomus, CUVIER, 1818, (Pisces: Characiformes), confinado en jaulas flotantes. Saber, v.12, p.3-7, 2000.

GREENBERG, A.E.; CLESCERI, L.S.; EATON, A.D. Standard methods for the examination of water and wastewater. $18^{\text {th }}$ ed. New York: American Public Health Association, 1992.

HARGREAVES, J.A. Photosynthetic suspended-growth systems in aquaculture. Aquaculture Engineering, v.34, p344-363, 2006.

JUÁREZ-PALACIOS, J.R. Avances en el cultivo de peces del genero Colossoma. Roma: FAO, 1989. 245p. (FAO. Proyecto AQUILA II. Documento de campo, 5).

MCINTOSH, R.P. Changing paradigms in shrimp farming: IV. Low-protein feeds and feeding strategies. Global Aquaculture Advocate, v.3, p.44-50, 2000. 
MCINTOSH, R.P. Changing paradigms in shrimp farming: V. Establishment of heterotrophic bacterial community. Global Aquaculture Advocate, v.4, p.53-58, 2001.

PRADA, C. Densidades y niveles de suministro de alimento en el cultivo de cachama (Colossoma macropomum, Cuvier 1818). Bioagro, v.2, p.7-25, 1982.

RAKOCY, J.E. An integrated fish and field crop system for arid areas. In: COSTS-PIERCE, B.A. (Ed.). Ecological aquaculture: the evolution of the blue revolution. Oxford: Blackwell Science, 2002. p.263-285.

RAKOCY, J.E. Tank culture of tilapia. Stoneville: Southern Regional Aquaculture Center, 1989. (SRAC. Publication, 282).

RAKOCY, J.E.; BAILEY, D.S.; MARTIN, J.M.; SHULTZ, R.C. Tilapia production systems for the Lesser Antilles and other resource-limited, tropical areas. In: INTERNATIONAL SYMPOSIUM ON TILAPIA IN AQUACULTURE, 5., 2000, Rio de Janeiro. Proceedings. Rio de Janeiro: Ministry of Agriculture, 2000. p.651-662.
SERFLING, S.A. Microbial flocs: natural treatment method supports fresh-water, marine species in recirculating systems. Global Aquaculture Advocate, v.9, p.34-36, 2006.

SILVA-ACUÑA, A.; GUEVARA, M. Evaluación de dos dietas comerciales sobre el crecimiento del híbrido de Colossoma macropomum x Piaractus brachypomus. Zootecnia Tropical, v.20, p.449-459, 2002.

SPARRE, P.; VENEMA, S.C. Introduction to tropical fish stock assessment. Rome: FAO, 1998. 407p. (FAO. Fisheries technical paper, 306).

IBM. IBM SPSS statistics 19. Chicago: IBM, 2007. Disponible en: <http://www.spss.com>. Accedido el: 20 mayo 2011.

TIMMONS, M.B.; EBELING, J.M.; WHEATON, F.W.; SUMMERRFELT, S.T.; VINCI, B.J. Recirculating aquaculture systems. $2^{\text {nd }}$ ed. New York: Cayuga Aqua Venture, 2002. 769p.

VILLACORTA-CORREA, M.A.; SAINT-PAUL, U. Structural indexes and sexual maturity of tambaqui Colossoma macropomum (Cuvier, 1818) (Characiformes: Characidae) in central Amazon, Brasil. Revista Brasileira de Biologia, v.59, p.637-652, 1999.

$\overline{\text { Recibido en } 23 \text { de noviembre de } 2010 \text { e aprobado en } 7 \text { de marzo de } 2011}$ 